\title{
US Environmental Protection Agency's framework for human health risk assessment to inform decision making
}

\author{
Julie Fitzpatrick* \\ Risk Assessment Forum, \\ Office of the Science Advisor, \\ US Environmental Protection Agency, \\ 1200 Pennsylvania Avenue NW, \\ Washington DC 20460, USA \\ Email: Fitzpatrick.Julie@epa.gov \\ *Corresponding author
}

\section{Rita Schoeny}

Office of Research and Development,

US Environmental Protection Agency,

726 5th Street NE, Washington DC 20002, USA

Email: ritas50@verizon.net

\section{Kathryn Gallagher}

Chief Ecological Risk Assessment Branch,

Office of Water,

US Environmental Protection Agency,

1200 Pennsylvania Avenue NW,

Washington DC 20460, USA

Email: Gallagher.kathryn@epa.gov

\section{Kathleen Deener}

Office of Research and Development,

US Environmental Protection Agency,

1200 Pennsylvania Avenue NW,

Washington DC 20460, USA

Email: Deener.kathleen@Epa.gov 


\section{Chris Dockins}

National Center for Environmental Economics,

Office of Policy,

US Environmental Protection Agency,

1200 Pennsylvania Avenue NW,

Washington DC 20460, USA

Email: Dockins.chris@epa.gov

\section{Michael Firestone}

Office of Children's Health Protection,

US Environmental Protection Agency,

1200 Pennsylvania Avenue NW,

Washington DC 20460, USA

Email: Firestone.michael@epa.gov

\section{William Jordan}

Office of Pesticide Programs,

Office of Chemical Safety and Pollution Prevention,

US Environmental Protection Agency,

1200 Pennsylvania Avenue NW,

Washington DC 20460, USA

Email: Jordan.william@epa.gov

\section{Margaret McDonough}

US Environmental Protection Agency,

Region 1, 5 Rock Slide Ct,

Greenville, SC 29615, USA

Email: margaretrmcdonough@gmail.com

\section{Deirdre Murphy}

Office of Air and Radiation,

US Environmental Protection Agency,

109 T.W. Alexander Drive,

Research Triangle Park, NC 27709, USA

Email: Murphy.deirdre@epa.gov 


\title{
Marian Olsen
}

Emergency and Remedial Response Division, US Environmental Protection Agency, Region 2, 290 Broadway, 18th Floor, New York, NY 10007, USA

Email: Olsen.marian@epa.gov

\section{Kathleen Raffaele}

Office of Land and Emergency Management, US Environmental Protection Agency, 1200 Pennsylvania Avenue NW, Washington DC 20460, USA

Email: Raffaele.kathleen@epa.gov

\begin{abstract}
The US Environmental Protection Agency (EPA) has developed a framework for human health risk assessment to inform decision making. The National Research Council, in Science and Decisions, recommended that EPA adopt a framework for risk-based decision making, which maximises the utility of risk assessment. The framework considers the NRC's recommendations and builds upon existing agency guidance by emphasising the need to design risk assessments to provide information most applicable to the decision-making process. The framework ties together existing human health guidance, is flexible to accommodate the range of assessments conducted across the agency as well as future advances in risk assessment science, and considers overarching themes including environmental justice and susceptible lifestage risk. The framework integrates the concepts of planning and scoping and problem formulation and provides for incorporation of stakeholder involvement and peer review.
\end{abstract}

Keywords: risk assessment; decision-making; science and decisions; risk assessment design, risk assessment utility.

Reference to this paper should be made as follows: Fitzpatrick, J., Schoeny, R., Gallagher, K., Deener, K., Dockins, C., Firestone, M., Jordan, W., McDonough, M., Murphy, D., Olsen, M. and Raffaele, K. (2017) 'US Environmental Protection Agency's framework for human health risk assessment to inform decision making', Int. J. Risk Assessment and Management, Vol. 20, Nos. 1/2/3, pp.3-20.

Biographical notes: Julie Fitzpatrick is the Human Health Science Coordinator for the US Environmental Protection Agency's Risk Assessment Forum. She has more than 25 years professional experience focused on human health risk assessment. She leads the Risk Assessment Forum's effort to respond to the National Research Council's recommendations focusing on advancing human health risk assessment. Previously, she managed expert working groups, for the International Life Sciences Institute (ILSI) Research Foundation in advancing risk assessment science. Her experience also includes providing risk assessment technical support in US EPAs Region 4 office, independent risk assessment consulting services, and technical and project management staff at several environmental consulting firms. She is the Past Chair of the Society for Risk Analysis' Dose Response Specialty Group. She received her Master of Science degree from Georgia Institute of Technology and is a member of the Society of Toxicology. 
Rita Schoeny recently retired from the US Environmental Protection Agency. Prior to her retirement, she was a Senior Science Advisor in both the Office of Research and Development and the Office of Water. She received her PhD in Microbiology from the School of Medicine, University of Cincinnati. She holds a Post-Doctoral Fellowship in the Department of Environmental Health at the Kettering Laboratory, she was appointed as an Assistant Professor in that department at the UC Medical School. She has held several adjunct appointments and regularly lectures at colleges and universities on risk assessment.

Kathryn Gallagher is the Branch Chief for the Ecological Risk Assessment Branch in EPAs Office of Water, leading a team of scientists in developing aquatic life water quality criteria. She earned her $\mathrm{PhD}$ from the College of William and Mary, where her research was focused on the occurrence and effects of organic chemicals in estuarine systems. She conducted her Post-Doctoral Research at NIHs National Institute of Environmental Health Sciences in Comparative Toxicology. She has held a number of positions at EPA. She has served as the Branch Chief of the Science Support Branch in the Office of Pollution Prevention in Toxics, the Executive Director of the Risk Assessment Forum, the Science and Technology Policy Council Staff Team Leader, the Toxics Coordinator for the Chesapeake Bay Program, and as an ecological risk assessor in the Office of Pesticide Programs.

Kathleen Deener is a Senior Science Advisor in EPAs Office of Research and Development (ORD), where she provides science and policy support and advice to the Deputy Assistant Administrator of ORD, who also serves as the Agency's Science Advisor. Prior to this, she served as the Director of the Communications and Regulatory Support for EPAs National Center for Environmental Assessment (NCEA), where she managed communications, outreach, and stakeholder engagement and provided advice on science policy issues. She has 20 years of experience in the private and public sectors spanning science, research, policy, and communication. She holds an MPH with specialisation in Environmental Health, the Risk Sciences and Public Policy from the Johns Hopkins Bloomberg School of Public Health.

Chris Dockins is a Senior Economist in the EPAs National Center for Environmental Economics. His work focuses on benefit-cost analysis, including research on the valuation of health risk reductions and the relationships between risk assessment and economics. He is an instructor with Johns Hopkins University and his academic background includes a $\mathrm{PhD}$ in Economics from Duke University.

Michael Firestone is the Senior Scientist in EPAs Office of Children's Health Protection. He has been involved in the development of many important EPA risk assessment guidance documents including: Exposure Assessment Guidelines; Guiding Principles for Monte Carlo Analysis; Guidance on Cumulative Risk Assessment Planning and Scoping; Guidelines for Carcinogen Risk Assessment and Supplemental; Guidance for Assessing Susceptibility from Early-Life Exposure to Carcinogens; Guidance on Selecting Age Groups for Monitoring and Assessing Childhood Exposures to Environmental Contaminants (2006); and Framework for Human Health Risk Assessment to Inform Decision Making. He led the development of EPAs Risk Assessment Portal and EPAs Strategic Plan for Evaluating the Toxicity of Chemicals. $\mathrm{He}$ helped develop the agency's Children's Environmental Health Research Roadmap and has participated on several important regulatory development projects to control lead, perchlorate, and protect pesticide workers. 
William Jordan is the Former Deputy Director in EPAs Office of Pesticide Programs. His responsibilities with EPA included the oversight of science policies and risk assessment procedures.

\begin{abstract}
Margaret McDonough was an environmental scientist at the US Environmental Protection Agency's regional office in Boston, MA for over 30 years. She assessed risks associated with human exposure to chemicals in soil, air, water and biota for numerous hazardous waste sites. She was an active participant in workgroups that developed national guidance and policy documents addressing risk assessment. She holds an MS in Environmental Health.
\end{abstract}

Deirdre Murphy is a Scientist with the Office of Air and Radiation in the US Environmental Protection Agency, where she leads reviews of national ambient air quality standards for the protection of public health and welfare, and characterises key policy aspects of standards decisions. She is also involved in interpretations of hazard and risk associated with hazardous air pollutants. Her background is in toxicology and environmental sciences. She is a member of Society of Toxicology and of the Society of Environmental Toxicology and Chemistry.

Marian Olsen is a Senior Human Health Risk Assessor in US EPA Region 2 Emergency and Remedial Response Division working on the assessment of risks at abandoned hazardous waste sites. She holds a Doctor in Public Health in Environmental Health Sciences as well as a Masters of Public Health in the same field. She works in the application of risk assessment to inform decisions at Superfund Sites.

Kathleen Raffaele is a Senior Toxicologist at the US Environmental Protection Agency, currently working as a Senior Science Advisor in the Office of Land and Emergency Management. She holds a PhD and Master's of Public Health in Environmental Health Science. Her areas of expertise include neurotoxicology and risk assessment, and she currently serves as the Chair of EPAs Risk Assessment Forum's Human Health Oversight Committee.

This paper is a revised and expanded version of a paper entitled 'US EPA's framework for human health risk assessment to inform decision making' presented at Risk Science in the 21st Century, Ottawa, 4-6 March 2013.

\title{
1 Introduction
}

Risk assessment has informed decisions made to protect human health and the environment since the inception of the US Environmental Protection Agency (US EPA). The Framework for Human Health Risk Assessment to Inform Decision Making (Framework) (US EPA, 2014) draws on Agency experience and addresses the recommendations on risk assessment process from the National Research Council's (2009) report, Science and Decisions: Advancing Risk Assessment, also known as the Silver Book. This Framework seeks to address Silver Book recommendations on the design of risk assessments and opportunities for improving their utility. The Framework draws on a considerable body of additional expert advice, beginning with the NRC's (1983) report, Risk Assessment in the Federal Government: Managing the Process (commonly referred to as the Red Book), followed by the NRC's (1994) report, Science 
and Judgment in Risk Assessment (commonly referred to as the Blue Book), and principles from the agency's extensive human health risk assessment guidance. In US EPA (1984), the agency issued Risk Assessment and Management: Framework for Decision Making, which first articulated EPAs risk assessment framework. Shortly thereafter EPA began issuing a series of risk assessment guidelines for various aspects of risk assessment (e.g., cancer, chemical mixtures, developmental toxicity, exposure assessment, mutagenicity, neurotoxicity, and reproductive toxicity) (US EPA 1986a, 1987, 2005, 1986c, 2000a, 1991a, 1992a, 1986b, 1998a, 1996). EPAs efforts to advance risk assessment practice have been in parallel with many other efforts including those of the World Health Organization/International Programme on Chemical Safety, the International Life Sciences Institute and the Alliance for Risk Assessment (Pastoor et al., 2014; Dourson et al., 2013; Munns et al., 2003; Birnbaum et al., 2001).

In emphasising the planning aspects of risk assessments, the framework builds on principles of EPAs 1997 Guidance on Cumulative Risk Assessment: Part 1: Planning and Scoping, which described an approach where risk assessors and managers work together to plan the purpose, scope, and technical approach for risk assessments (US EPA, 1997). The 1997 guidance augmented the Agency's 1995 Guidance for Risk Characterization (US EPA, 1995) by emphasising the need for providing a transparent, clear, consistent and reasonable basis for any assessment, as well as encouraging a formal problem formulation exercise for all risk assessments. In 1997, the agency also published the Framework for Ecological Risk Assessment (US EPA, 1992b) and subsequently released the Guidelines for Ecological Risk Assessment (US EPA, 1998a), which incorporated planning and scoping into the ecological risk assessment process. In 2003, the Framework for Cumulative Risk Assessment (US EPA, 2003a) further built on these documents in formulating a flexible structure for conducting a risk assessment to evaluate cumulative human health or ecological risk. In 2006, the agency published A Framework for Assessing Health Risk of Environmental Exposures to Children, which applied this general structure in describing risk assessments focused on evaluating potential risks arising as a result of early life exposure (US EPA, 2006).

The Framework highlights the interaction between risk assessment and decision making, focusing on optimising the utility of a risk assessment to aid in making choices among options. In this context, a well-conducted, useful risk assessment is one that specifically fits its intended purpose. In addition, the context (e.g., regulatory decision making) will affect the risk assessment in many ways. It is important to note, however, that EPA maintains the conceptual distinction between risk assessment and risk management, as described in the Red Book (NCR, 1983); the Framework does not allow for the manipulation of the risk assessment to support predetermined policy or management choices. As articulated by the NRC (2009) in the Silver Book, "[T]he conduct of risk assessments used to evaluate the risk-management options [is] in no way to be influenced by the preferences of risk managers".

The Framework describes a process for conducting human health risk assessments that are responsive to EPAs decision-making needs while providing an organising structure for implementing existing and future EPA guidance on human health risk assessment. Rather than establishing new guidance, the Framework compiles existing Agency policy, guidance and guidelines into a single coherent document. The Framework highlights the role of planning and scoping in designing a risk assessment that serves its intended purpose, as well as the importance of scientific peer review and public, stakeholder and community involvement. The Framework moves the agency 
forward in harmonisation of human health and ecological risk assessment methodology. The Framework is designed to promote and increase the transparency of the EPA human health risk assessment processes, following the general principles presented in Table 1.

Table 1 General principles of the Framework for Human Health Risk Assessment to Inform Decision Making

- A risk assessment should be fit for its intended purpose.

- A risk assessment should state its purpose, context and scope clearly.

- Risk assessments should be based on exposure scenarios that are consistent with the purpose and context. As appropriate, they should include consideration of susceptible population groups and life stages.

- Risk assessments should follow an acceptable, overtly logical path, employing common sense and sound judgment in applying relevant guidance.

- All steps, key assumptions, limitations and decisions, as well as associated rationales.

Source: US EPA (2014)

\subsection{Fit for purpose}

Risk assessments at EPA are performed to inform decisions. Thus, while planning and performing the analyses, it is important to confirm that the assessment will address the information needs of the decision makers. In the Silver Book (NCR, 2009), the NRC recommended the use of a framework that "maximizes the utility of risk assessment," with a focus on assuring that risk assessments are well-tailored to the problems and decisions at hand so to inform the decision-making process most meaningfully. In the Framework, EPA introduces the concept of 'fit for purpose' to characterise risk assessments designed to maximise the utility of risk assessments for agency decision making. Associated work outside of the Agency addressing 'fit for purpose' has been conducted through a workshop series under the auspices of the Alliance for Risk Assessment (Meek et al., 2013).

The utility of a risk assessment is not evaluated as a separate step in the process or in a final check that occurs once the risk assessment is completed. Instead, consistent with the NRCs emphasis on consideration of a decision maker's needs early in the process, the Framework emphasises attention to utility throughout the process, beginning with planning and scoping, and including a specific focus on the applicability of the risk assessment for informing decisions. This is done through focused planning and problem formulation, as well as during the process, to ensure that the informational needs for the decision makers are met by the information being generated by the assessment. The overarching questions in addressing 'fit for purpose' are these:

- Does the assessment inform choices among options?

- Will the risk assessment need to be changed or expanded to discriminate between options?

Questions to consider in evaluating the usefulness of the risk assessment design and its implementation include those listed below: 
- Does the risk assessment design meet the objectives?

- Does the assessment, as implemented, meet the initial objectives, and is it consistent with the planned attributes? If the initially identified objectives or attributes have been modified, does the assessment incorporate the modifications?

- If the assessment requires peer review, has this been done appropriately, and have the issues raised during the peer review been addressed adequately?

- How will the results of the risk assessment be communicated to decision makers and stakeholders?

Depending on the answers to these and other questions, additional or revised analyses may be considered in the assessment in order to address the specific options being considered.

\subsection{Framework overview}

The main elements of the Framework as shown in Figure 1 are:

Figure 1 Framework for human health risk assessment to inform decision making

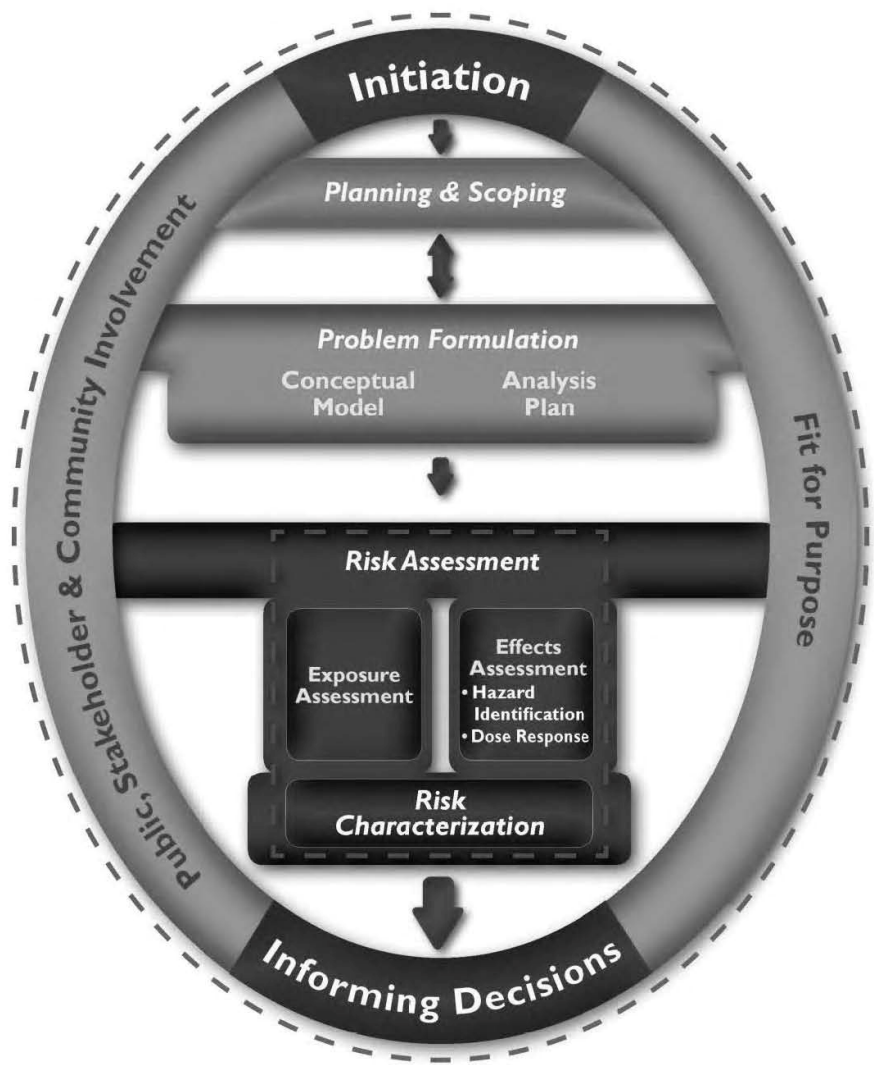


- planning and scoping and problem formulation

- public, stakeholder and community involvement

- risk assessment including exposure and effects assessment and risk characterisation

- informing decisions.

EPA risk assessments address overarching themes including children's environmental health protection, cumulative risk assessment, environmental justice and sustainability. These overarching considerations may not affect all analyses; early consideration and discussion of these issues, however, can enhance the utility of the risk assessment. These considerations alternatively or additionally may receive particular attention in the risk management arena, depending on the decision context. Such attention may be independent of a risk assessment and may require additional data to address one or more of the overarching considerations.

The risk assessment may be evaluated via independent peer review and may receive input from public, stakeholder and/or community involvement, recognising that approaches for addressing these different audiences will vary among assessments. Independent peer review helps to ensure the integrity and quality of the scientific and technical aspects of the risk assessment.

\section{Initiation of the risk assessment process}

The Silver Book (NCR, 2009) noted that the risk assessment process begins with a decision to conduct a risk assessment based on a 'signal' of potential harm. The initiation of the EPA risk assessment occurs within a larger decision-making process. It is important that planning for the risk assessment include consideration of the decisions that the assessment is being conducted to inform. International Life Sciences Institute's (ILSIs) RISK21 project addresses problem formulation, utilising existing information, and initiation of the risk assessment process focused on exposure rather than toxicity (Pastoor et al., 2014).

\subsection{Planning and scoping}

Planning and scoping is an important first step to ensure that each risk assessment has a clear purpose and well-defined vision and is critical to producing a sound risk assessment that serves its intended purpose (NCR, 2009; Presidential/Congressional Commission on Risk Assessment and Risk Management, 1997a, 1997b; US EPA, 1997, 1998b, 2000b, 2002a, 2003a, 2006). Questions addressed in the planning and scoping step (derived from US EPA, 1997) are as follows:

- What are the overall purposes and general scope of the risk assessment? Are there legal limitations or other legal considerations? If so, what are they?

- What risk assessment products (quantitative and qualitative) are needed by management for informed decision making? What is needed for other analyses (e.g., economic analysis)? 
- What resources are required, available or pending? Resources could include data or models, funding, personnel, expertise and/or coordination with other organisations.

- Who will be involved in conducting the risk assessment, and what are their roles (e.g., technical, legal, or stakeholder)?

- What schedule will be followed? This will include provision for timely input to the decision-making process including internal and independent external peer review, where appropriate.

In general, planning and scoping provides the opportunity for decision makers, risk assessors and others interested in the process to consider the context in which the risk assessment is being conducted and the purpose(s) for which the results will be used. In this stage, risk assessors and decision makers discuss the options to be considered along with any aspects of the risk assessment design for which there are policy implications. Planning and scoping results in a common understanding of the boundaries for the risk assessment and the process for how it will be conducted.

\subsection{Problem formulation}

Problem formulation systematically identifies the major factors to be considered in the assessment. It draws from the regulatory, decision making and policy context of the assessment and informs the assessment's technical approach. EPAs Guidelines on Ecological Risk Assessment defines problem formulation as the analytical phase of the assessment in which "the purpose for the assessment is articulated, the problem is defined, and a plan for analyzing and characterizing risk is determined" [US EPA, (1998b), p.2]. The formalisation of this step is significant in harmonising human health and ecological risk assessment across EPA and key in ensuring that risk assessments are 'fit for purpose'.

The outcomes of problem formulation are the conceptual model and analysis plan. The conceptual model, through the use of a written description and visual representation, identifies the stressor(s), the exposed population(s) and the endpoint(s) that will be addressed in the risk assessment, as well as the relationships among them. The analysis plan, which describes the approach for the risk assessment and how it will address the Agency's needs, is developed in light of the conceptual model, any programmatically established assessment endpoints, and other planning considerations.

\section{Public, stakeholder and community involvement}

Effective public involvement can enhance the deliberative process and improve the content of the Agency's decisions (US EPA, 2003b). It provides EPA with the opportunity to obtain and consider a range of views on the issue being assessed, as well as on the options being considered. The Framework calls for public, stakeholder and community involvement at key points in the risk assessment process. The timing, frequency and level of involvement will depend on a number of factors, including regulatory requirements, the nature of the decision, and community, stakeholder and public interest. 
EPAs Public Involvement Policy [US EPA, (2003b), p.1] states that "EPA staff and managers should seek input reflecting all points of view and should carefully consider this input when making decisions." In addition, the policy states that "EPA should not accept any recommendation or proposal without careful, critical examination" [US EPA, (2003b), p.1].

Individuals and groups decide for themselves whether, when and how to participate. It is recognised that not everyone chooses to be an active participant in providing input (e.g., facts, data, opinions) to policy or regulatory decisions of the agency.

\section{Risk assessment}

Risk assessments conducted for EPA range from relatively simple to complex, depending on factors including the decision being made and the availability of relevant data. The analyses that contribute to a risk assessment may range from those based on default assumptions to more refined analyses that include site-specific information and quantitative uncertainty assessment, consistent with agency policies and guidance (US EPA, 1992a, 2005, 2011a). Planning and scoping identifies the level of assessment appropriate for the needs of the decision maker and the role that risk information plays in the decision. The assessment is then structured around the conceptual model and analysis plan generated in problem formulation. The steps in risk assessment often are performed together, in an integrative fashion, rather than as a linear or sequential process. As information is developed and preliminary conclusions are drawn, it is not uncommon to revisit data needs or revise the conceptual model and analysis plan.

\subsection{Exposure assessment}

Exposure assessment is one of the primary components of risk assessment; it describes how humans come into contact with hazards (Cohen-Hubal et al., 2011; IPCS, 2004). The approaches employed for this component may vary across risk assessments to reflect considerations described in the conceptual model and analysis plan, as well as regulatory needs. The Guidelines for Exposure Assessment provides principles, concepts and methods used by EPA in evaluating exposures (US EPA, 1992a). The use of exposure science have been instrumental in forecasting, preventing and mitigating exposures that lead to adverse human health outcomes (Cohen-Hubal et al., 2010). Exposure assessment addresses the intensity and duration of human contact with different types of stressors (e.g., chemical, physical, and biological) and their fate in living systems, including vulnerable populations and susceptible life stages (NCR, 2012).

A key aspect of all exposure assessments is the consideration of the potential existence of susceptible or more highly exposed populations or lifestages. Based on considerations and decisions in the conceptual model, quantitative exposure assessments may include the development of estimates specific to these populations or life stages (Firestone et al., 2007; Firestone, 2010). EPAs Exposure Factors Handbook and Child-Specific Exposure Factors Handbook provide a compendium of exposure factors for a number of parameters for adults and children, including such metrics as ingestion of soil, time spent in residence, surveys of fish ingestion, ingestion of homegrown products and inhalation rates (US EPA, 2008, 2011a; Phillips and Moya, 2014). 


\subsection{Effects assessment}

In human health risk assessment, the characterisation of effects includes hazard identification and dose-response assessment. The approaches employed for these components vary across different risk assessments and will reflect considerations described in the conceptual model and analysis plan.

Hazard identification is the process of identifying the type of human health hazard (e.g., cancer and birth defects) that might result from exposure to a substance of interest for a given risk assessment. Hazard identification for most agency risk assessments focuses on chemical agents, though EPA may also look at other stressors (e.g., chemical, biological, social or physical) (US EPA, 2003a). In the case of chemical agents, the process examines the available scientific data for a given chemical (or group of chemicals) and develops a characterisation of hazard. This requires identifying, evaluating and synthesising information to describe the health effects of individual chemicals or chemical mixtures. Studies evaluated may include human clinical or epidemiological studies, in vivo or in vitro laboratory animal studies, or mechanistic or kinetic studies in a variety of test systems. In recent years, risk assessors have begun to consider additional types of data during hazard identification, for example, those from computational toxicology (quantitative structure-activity relationships, high-throughput assays) and genomic response assays. Other data types may be identified in the future. Key aspects of hazard identification include consideration of available information on toxicokinetics (i.e., how the body absorbs, distributes, metabolises and excretes chemicals) and toxicodynamics (i.e., the effects that chemicals have on the body), as well as potential modes of action (or toxicity pathways) related to the health effects identified.

In hazard identification, the strengths and limitations of the data and information used to support the weight of evidence are described, including areas for which data may be unavailable (data gaps). In situations where a quantitative risk assessment is to be performed, a particular study or group of studies may be identified for use in doseresponse assessment.

Dose response characterises the relationship between the exposure or dose of a contaminant and the occurrence of particular health effects or outcomes. Drawing from the conceptual model and analysis plan, the dose-response assessment (US EPA, 2012) may be developed using a combination of data, science policy decisions and models. The assessment also may include the derivation of an established metric, such as an oral reference dose and inhalation reference concentration and an oral slope factor and inhalation unit risk (for cancer effects) (US EPA, 2002b).

\subsection{Risk characterisation}

Risk characterisation integrates exposure assessment and effects assessment into quantitative and qualitative estimates of risk for the evaluated population(s) (US EPA, 2011b). The Agency's Risk Characterization: Science Policy Council Handbook (US EPA, 2000b) describes risk characterisation as the step that "integrates information from the preceding components of the risk assessment and synthesizes an overall conclusion about the risk that is complete, informative, and useful for decision makers".

Risk characterisation restates the scope of the assessment, expresses results clearly, articulates major assumptions and uncertainties, identifies reasonable alternative interpretations, and separates scientific conclusions from policy judgements (US EPA, 
2011b). EPA's risk characterisation policy calls for conducting risk characterisations in a manner that is consistent with the following principles:

- Transparency: The characterisation should fully and explicitly disclose the risk assessment methods, default assumptions, logic, rationale, extrapolations, uncertainties, and overall strength of each step in the assessment.

- Clarity: The products from the risk assessment should be readily understood by readers who were involved and not involved in the specific risk assessment process. Documents should be concise, be free of jargon, and use understandable tables, graphs and equations as needed.

- Consistency: The risk assessment should be conducted and presented in a manner that is consistent with EPA policy and other risk characterisations of similar scope prepared across programs within EPA.

- Reasonableness: The risk assessment should be based on sound judgement, with methods and assumptions consistent with the current state-of-the-science and conveyed in a manner that is complete, balanced and informative.

A risk characterisation conveys the nature and presence or absence of risks in quantitative and qualitative terms. It describes information on how the risks were assessed, where assumptions and uncertainties still exist, and where policy choices will need to be made. If numerical estimates of effects or exposure are not done, qualitative estimates may be used to characterise risk. It is the role of the risk assessor to provide a transparent description of all aspects of the risk assessment (e.g., default assumptions and data selected) to make clear the range of plausible risks associated with each option. Clear communication between the risk assessors and decision maker is vital to assuring that risk information is conveyed appropriately.

Whatever approach is used to estimate risk, it is important to be clear in describing the range of possible risks (including central tendency and high end portions of the risk distribution), as well as important subgroups such as highly exposed or highly susceptible groups. For example, the extent to which the assessment may underestimate or overestimate risk for some populations should be highlighted to inform the decision-making appropriately. Uncertainties may be characterised quantitatively (e.g., using probabilistic methods) or qualitatively (e.g., describing how the results would change if the data were interpreted differently). The risk assessment characterises the nature and magnitude of risk and who is at risk under different options (including a status quo option, where appropriate).

\section{Informing decisions}

EPA uses risk assessment as a key source of scientific information for evaluating risks and related outcomes associated with possible options. Risk assessments that are well-planned and focused will be most useful and informative for decision making (Presidential/Congressional Commission on Risk Assessment and Risk Management, 1997a, 1997b). 
EPA makes many types of decisions that cover a wide range of environmental issues and pollutants. Each of these decisions is made in the context of a combination of statutes, precedents and stakeholders. The statutes establish legal requirements that generally describe the protection that EPA regulations must achieve; they also may specify aspects of the risk assessment. Statutes may identify other factors in the regulatory decision, such as consideration of best available control technologies, and cost and benefit considerations. Accordingly, how risk assessment informs decision-making may be affected by such statutory or regulatory requirements and restrictions, or by regulations established by states and tribal nations.

The information specific to the decision should be provided as clearly, completely and objectively as possible. The informational needs will have been identified as part of planning and scoping, and are updated and refined throughout the assessment process to ensure that the risk assessment is fit-for-purpose. Much of this information will be in the risk characterisation and is based on transparency in conducting and explaining the risk assessment combined with clarity, consistency and reasonableness in the preparation of the risk description (US EPA, 2000b). The science supporting the risk assessment conclusions, as well as consideration of variability, susceptibilities and uncertainties, informs decisions among the options presented in the risk assessment (Morgan et al., 1990).

In this step of the process, the goal of the risk assessment team ultimately is to paint as complete a picture as possible regarding risk for a range of possible options. The description of the decision should clarify how the risk assessment and other factors informed the decision.

\section{Summary}

The Framework for Human Health Risk Assessment to Inform Decision Making lays out a framework for conducting human health risk assessments in support of decision-making at EPA. It focuses on the planning and scoping and problem formulation steps, drawing on EPA experience and recommendations from the NRC and other advisory groups. For example, the Framework addresses recommendations in the Silver Book (NCR, 2009) on assuring the utility of risk assessment, which the Framework terms as being fit for purpose.

The NRC's (1983) four-step risk assessment paradigm is maintained, but there is increased emphasis on interaction between risk assessors and decision makers in planning the assessment to maximise utility. Emphasis on utility for informing decision making is maintained throughout the process, beginning with planning and scoping and continuing through the evaluation of the applicability of the risk assessment in informing decisions. The Framework highlights the practical nature of risk assessment. Although the agency is committed to advancing risk assessment science, assessments are not academic exercises. Instead, they are intended to support decision-making for the protection of human health. Application of the Framework, with its emphasis on problem formulation and the utility of the risk assessment, ultimately will result in better, more transparent choices among options.

The Framework includes a foundation quite similar to that in EPAs Framework for Ecological Risk Assessment (US EPA, 1992b), thus illustrating conceptual similarity between the two types of risk assessment. The Framework builds on agency guidelines, 
policies and guidance and is directed at improving risk assessment products, but it does not overturn or in any way change existing science policy decisions.

The Framework's explicit recognition of the roles for planning and scoping; public, stakeholder and community involvement; and consideration of utility will assist in developing risk assessments focused on informing decisions. Furthermore, institutionalisation of the Framework for Human Health Risk Assessment to Inform Decision Making will contribute transparency to the agency's risk assessment process and a level of consistency across assessments, media and programs, as well as between human health and ecological outcomes.

\section{Framework development}

The Framework was developed by a Technical Panel under the auspices of the EPAs Risk Assessment Forum. The Risk Assessment Forum is a standing committee of senior EPA scientists that was established to promote Agency-wide consensus on risk assessment issues and to ensure that this consensus is incorporated into appropriate agency risk assessment guidance. A draft Framework was released for public comment, inter-agency comment, and external peer review in July 2012. An external peer review meeting was held in September 2012. The draft Framework was subsequently revised to address input from the public, interagency partners, and external peer review prior to being released in April 2014.

\section{References}

Birnbaum, L., Damstra, T. and Hart, J. et al (2001) Integrated Risk Assessment, Report prepared for the WHO/UNEP/ILO International Programme of Chemical Safety, WHO/IPCS/IRA/01/12.

Cohen-Hubal, E.A., Barr, D.B., Koch, H.M. and Bahadori, T. (2011) 'The promise of exposure science', Journal of Exposure Science and Environmental Epidemiology, Vol. 21, No. 2, pp.121-122.

Cohen-Hubal, E.A., Richard, A.M., Aylward, L., Edwards, S.W., Gallagher, J., Goldsmith, M., Isukapalli, S., Tornero-Velez, R., Weber, E.J. and Kavlock, R.J. (2010) 'Advancing exposure characterization for chemical evaluation and risk assessment', Journal of Toxicology and Environmental Health, Part B Critical Reviews, Vol. 13, Nos. 2-4, pp.299-313.

Dourson, M., Becker, R., Haber, L., Pottenger, L., Bredfeldt, T. and Fenner-Crisp, P. (2013) 'Advancing human health risk assessment: integrating recent advisory committee recommendations', Critical Reviews in Toxicology, Vol. 43, No. 6, pp.467-492.

Firestone, M. (2010) 'Protecting children from environmental risks throughout each stage of their childhood', Journal of Exposure Science and Environmental Epidemiology, Vol. 20, No. 3, pp.227-228.

Firestone, M., Moya, J., Cohen-Hubal, E., Zartarian, V. and Xue, J. (2007) 'Identifying childhood age groups for exposure assessments and monitoring', Risk Analysis, Vol. 27, No. 3, pp.701-714.

International Programme on Chemical Safety (IPCS) (2004) IPCS Risk Assessment Terminology. Part 1: IPCS/OECD Key Generic Terms Used in Chemical Hazard/Risk Assessment: Part 2: IPCS Glossary of Key Exposure Assessment Terminology, International Programme on Chemical Safety, Harmonization Project Document No. 1, World Health Organization, Geneva [online] http://www.who.int/ipcs/methods/harmonization/areas/ ipcsterminologyparts1and2.pdf (accessed 22 December 2015). 
Meek, M.E., Bolger, M., Bus, J., Christopher, J., Conolly, R., Lewis, R.J., Paolini, G., Schoeny, R., Haber, L., Rosenstein, A. and Dourson, M. (2013) 'A framework for fit-for-purpose dose response assessment', Regulatory Toxicology and Pharmacology, Vol. 66, No. 2, pp.234-240.

Morgan, M.G., Henrion, M. and Small, M. (1990) Uncertainty: A Guide to Dealing with Uncertainty in Quantitative Risk and Policy Analysis, Cambridge University Press, Cambridge, MA.

Munns, W., Kroes, R., Veith, G., Suter II, G.W, Damstra, T. and Waters, M. (2003) 'Approaches for integrated risk assessment', Human and Ecological Risk Assessment, Vol. 9, No. 1, pp.267-272.

National Research Council (NRC) (1983) Risk Assessment in the Federal Government: Managing the Process, The National Academies Press, Washington, DC [online] http://www.nap.edu/openbook.php?isbn=0309033497 (accessed 22 December 2015).

National Research Council (NRC) (2009) Science and Decisions: Advancing Risk Assessment, The National Academies Press, Washington, DC [online] http://www.nap.edu/ catalog.php?record_id=12209 (accessed 22 December 2015).

National Research Council (NRC) (2012) Exposure Science in the 21st Century, The National Academies Press, Washington, DC [online] http://www.nap.edu/catalog.php?record id=13507 (accessed 22 December 2015)

Pastoor, T., Bachman, A., Bell, D., Cohen, S., Dellarco, M., Dewhurst, I., Doe, J., Doerrer, N., Embry, M., Hines, R., Moretto, A., Phillips, R., Rowland, J.C., Tanir, J., Wolf, D. and Boobis, A. (2014) 'A 21st century roadmap for human health risk assessment', Critical Reviews in Toxicology, Vol. 44, No. 1, pp.1-5.

Phillips, L., and Moya, J. (2014) 'Exposure factors resources: contrasting EPA's exposure factors handbook with international sources', Journal of Exposure Science and Environmental Epidemiology, Vol. 24, No. 3, pp.233-243.

Presidential/Congressional Commission on Risk Assessment and Risk Management (PCCRARM) (1997a) Framework for Environmental Health Risk Management, Vol. 1, Final Report, PCCRARM, Washington, DC [online] http://cfpub.epa.gov/ncea/risk/ recordisplay.cfm?deid $=55006 \&$ CFID $=53655091 \&$ CFTOKE $\mathrm{N}=46640861$ (accessed 22 December 2015).

Presidential/Congressional Commission on Risk Assessment and Risk Management (PCCRARM) (1997b) Risk Assessment and Risk Management in Regulatory Decision-Making, Vol. 2, Final Report, PCCRARM, Washington, DC [online] http://cfpub.epa.gov/ncea/risk/ recordisplay.cfm?deid $=55006 \&$ CFID $=53655091 \&$ CFTOKEN $=46640861$ (accessed 22 December 2015).

US Environmental Protection Agency (USEPA) (1984) Risk Assessment and Management: Framework for Decision Making, EPA/600/985/002, Office of Policy, Planning and Evaluation, Washington, DC [online] http://nepis.epa.gov/Exe/ ZyPURL.cgi?Dockey=20008KTF.txt. (accessed 22 December 2015).

US Environmental Protection Agency (USEPA) (1986a) Guidelines for Carcinogen Risk Assessment, EPA/630/R-00/004, Risk Assessment Forum, Washington, DC [online] http://www.epa.gov/risk/guidelines-carcinogen-risk-assessment (accessed 22 December 2015).

US Environmental Protection Agency (USEPA) (1986b) Guidelines for Mutagenicity Risk Assessment, EPA/630/R-98/003, Risk Assessment Forum, Washington, DC [online] $\mathrm{http}: / / \mathrm{www} . e p a . g o v /$ risk/guidelines-mutagenicity-risk-assessment (accessed 22 December 2015).

US Environmental Protection Agency (USEPA) (1986c) Guidelines for the Health Risk Assessment of Chemical Mixtures, EPA/630/R-98/002, Office of Research and Development, Washington, DC [online] http://www.epa.gov/risk/guidelines-health-riskassessment- chemical-mixtures (accessed 22 December 2015). 
US Environmental Protection Agency (USEPA) (1987) The Risk Assessment Guidelines of 1986, EPA/600/8-87/045, Office of Health and Environmental Assessment, Washington, DC [online] http://cfpub.epa.gov/ncea/cfm/recordisplay.cfm?deid=29777\#Download (accessed 22 December 2015).

US Environmental Protection Agency (USEPA) (1991a) Guidelines for Developmental Toxicity Risk Assessment, EPA/600/FR-91/001, Risk Assessment Forum, Washington, DC [online] http://www.epa.gov/risk/guidelines-developmental-toxicitrisk-assessment (accessed 22 December 2015).

US Environmental Protection Agency (USEPA) (1992a) Guidelines for Exposure Assessment, EPA/600/Z-92/001, Risk Assessment Forum, Washington, DC [online] http://www.epa.gov/risk/guidelines-developmental-toxicity-risk-assessment (accessed 22 December 2015).

US Environmental Protection Agency (USEPA) (1992b) Framework for Ecological Risk Assessment, EPA/630/R-92/001, Risk Assessment Forum, Washington, DC [online]

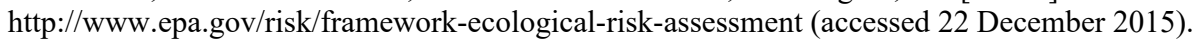

US Environmental Protection Agency (USEPA) (1995) Guidance for Risk Characterization, Science Policy Council, Washington, DC [online] http://itrcweb.org/FileCabinet/ GetFile?fileID=6870 (accessed 22 December 2015).

US Environmental Protection Agency (USEPA) (1996) Guidelines for Reproductive Toxicity Risk Assessment, EPA/630/R-96/009, Risk Assessment Forum, Washington, DC [online] http://www.epa.gov/risk/guidelines-reproductive-toxicity-risk-assessment (accessed 22 December 2015).

US Environmental Protection Agency (USEPA) (1997) Guidance on Cumulative Risk Assessment: Part 1: Planning and Scoping, Science Policy Council, Washington, DC [online] http://www.epa.gov/risk/guidance-cumulative-risk-assessment-part-1-planningand-scoping (accessed 22 December 2015).

US Environmental Protection Agency (USEPA) (1998a) Guidelines for Neurotoxicity Risk Assessment, EPA/630/R-95/001F, Risk Assessment Forum, Washington, DC [online] $\mathrm{http}: / / \mathrm{www} . e p a . g o v /$ risk/guidelines-neurotoxicity-risk-assessment (accessed 22 December 2015).

US Environmental Protection Agency (USEPA) (1998b) Guidelines for Ecological Risk Assessment, EPA/630/R-95/002F, Risk Assessment Forum, Washington, DC [online] http://www.epa.gov/risk/guidelines-ecological-risk-assessment (accessed 22 December 2015).

US Environmental Protection Agency (USEPA) (2000a) Supplementary Guidance for Conducting Health Risk Assessment of Chemical Mixtures, EPA/630/R-00/002, Risk Assessment Forum, Washington, DC [online] http://ofmpub.epa.gov/eims/ eimscomm.getfile?p_download_id=4486 (accessed 22 December 2015).

US Environmental Protection Agency (USEPA) (2000b) Risk Characterization: Science Policy Council Handbook, EPA/100/B-00/002, Science Policy Council, Washington, DC [online] http://www.epa.gov/risk/risk-characterization-handbook (accessed 22 December 2015).

US Environmental Protection Agency (USEPA) (2002a) Lessons Learned On Planning And Scoping For Environmental Risk Assessments, Science Policy Council Steering Committee, Washington, DC [online] http://nepis.epa.gov/Exe/ZyNET.exe/P1008PP7.TXT?

ZyActionD $=$ ZyDocument $\&$ Client $=$ EPA\&Index $=2000+$ Thru $+2005 \& D o c s=\& Q u e r y=\&$ Time $=\&$ EndTime $=\&$ SearchMethod $=1 \&$ TocRestrict $=$ n $\&$ Toc $=\&$ TocEntry $=\& Q$ Field $=\& Q$ Field Year $=\& Q$ FieldMonth $=\& Q$ FieldDay $=\&$ IntQFieldOp $=0 \&$ ExtQFieldOp $=0 \& X m 1$ uery $=\&$ File $=\mathrm{D} \% 3 \mathrm{~A} \% 5 \mathrm{Czy}$ files $\% 5 \mathrm{CIndex} \% 20 \mathrm{Data} \% 5 \mathrm{C} 00$ thru05\%5CTxt $\% 5 \mathrm{C} 00000025 \% 5 \mathrm{CP} 1008 \mathrm{P}$ P7.txt\&User $=$ ANONYMOUS\&Passwo $\mathrm{rd}=$ anonymous $\&$ SortMethod $=\mathrm{h} \% 7 \mathrm{C}-\&$ Maximum Documents $=1 \&$ FuzzyDegree $=0 \&$ ImageQuality $=$ r $75 \mathrm{~g} 8 / \mathrm{r} 75 \mathrm{~g} 8 / \mathrm{x} 150 \mathrm{y} 150 \mathrm{~g} 16 / \mathrm{i} 425 \&$ Display $=\mathrm{p} \%$ 7Cf\&DefSeekPage $=\mathrm{x} \&$ SearchBack $=$ ZyActionL\&Back $=$ ZyActionS\&Back Desc $=$ Results $\% 20$ page \&MaximumPages $=1 \& Z y$ Entry $=1 \&$ SeekPage $=x \& Z y P U R L$ (accessed 22 December 2015). 
US Environmental Protection Agency (USEPA) (2002b) A Review of the Reference Dose and Reference Concentration Processes, External Review Draft, EPA/630/P-02/002F, Risk Assessment Forum, Washington, DC [online] http://www.epa.gov/osa/ review-reference-dose-and-reference-concentration-processes (accessed 22 December 2015).

US Environmental Protection Agency (USEPA) (2003a) Framework for Cumulative Risk Assessment, EPA/630/P-02/001F, Risk Assessment Forum, Washington, DC [online] $\mathrm{http} / / /$ www.epa.gov/risk/framework-cumulative-risk-assessment (accessed 22 December 2015).

US Environmental Protection Agency (USEPA) (2003b) Public Involvement Policy, EPA/233/B-03/002, Office of Policy, Economics and Innovation, Washington, DC http://nepis.epa.gov/Exe/ZyNET.exe/100045RR.TXT?ZyActionD=ZyDocument\&Client=EP A\&Index $=2000+$ Thru $+2005 \&$ Docs $=\& Q u e r y=\&$ Time $=\&$ EndTime $=\&$ SearchMethod $=1 \&$ TocR estrict $=\mathrm{n} \& \mathrm{Toc}=\&$ TocEntry $=\& Q$ Field $=\& Q$ FieldYear $=\& Q$ FieldMonth $=\& Q$ FieldDay $=\& I n t Q F i$ eldOp $=0 \&$ ExtQFieldOp $=0 \& X m l Q u e r y=\& F i l e=D \% 3 \mathrm{~A} \% 5$ Czyfiles $\% 5$ CIndex $\% 20$ Data $\% 5 \mathrm{C} 00 \mathrm{t}$ hru05\%5CTxt $\% 5 \mathrm{C} 00000006 \% 5 \mathrm{C} 100045 \mathrm{RR} . \mathrm{txt} \& U$ ser $=$ ANONYMOUS\&Password=anonymo us\&SortMethod $=\mathrm{h} \% 7 \mathrm{C}-\&$ MaximumDocuments $=1 \&$ FuzzyDegree $=0 \&$ ImageQuality $=\mathrm{r} 75 \mathrm{~g} 8 /$ r75g8/x150y 150g16/i425\&Display $=$ p $07 C f \& D e f S e e k P a g e=x \& S e a r c h B a c k=$ ZyActionL\&Bac $\mathrm{k}=$ ZyActionS\&BackDesc $=$ Results\%20page $\&$ MaximumPages $=1 \& Z y$ Entry $=1 \&$ SeekPage $=\mathrm{x} \&$ ZyPURL (accessed 22 December 2015).

US Environmental Protection Agency (USEPA) (2005) Guidelines for Carcinogen Risk Assessment, EPA/630/P-03/001B, Risk Assessment Forum, Washington, DC [online]

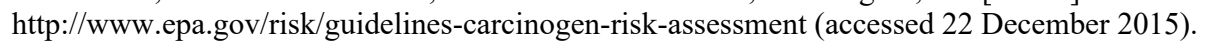

US Environmental Protection Agency (USEPA) (2006) A Framework for Assessing Health Risk of Environmental Exposures to Children, Final, EPA/600/R-05/093F, Office of Research and Development, National Center for Environmental Assessment, Washington, DC [online] http://cfpub.epa.gov/ncea/risk/recordisplay.cfm?deid=158363 (accessed 22 December 2015).

US Environmental Protection Agency (USEPA) (2008) Child-Specific Exposure Factors Handbook, Office of Research and Development, Washington, DC http://cfpub.epa.gov/ncea/risk/recordisplay.cfm?deid=199243 (accessed 22 December 2015).

US Environmental Protection Agency (USEPA) (2011a) Exposure Factors Handbook, EPA/600/ R-090/052F, Office of Research and Development, National Center for Environmental Assessment, Washington, DC [online] http://cfpub.epa.gov/ncea/risk/ recordisplay.cfm?deid=221023 (accessed 22 December 2015).

US Environmental Protection Agency (USEPA) (2011b) Risk Characterization, last modified 25 January 2011; EPA [online] http://www.epa.gov/risk/ conducting-human-health-risk-assessment\#tab-3 (accessed 22 December 2015).

US Environmental Protection Agency (USEPA) (2012) Step 2-Dose-Response Assessment, EPA [online] http://www.epa.gov/risk/conducting-human-health-riskassessment\# tab-3 (accessed 22 December 2015).

US Environmental Protection Agency (USEPA) (2014) Framework for Human Health Risk Assessment to Inform Decision Making, EPA/100/R-14/001, Risk Assessment Forum, Office of the Science Advisor, USEPA, Washington, DC [online] http://www.epa.gov/risk/ framework-human-health-risk-assessment-inform-decisionmaking (accessed 22 December 2015). 